\title{
The Use of Somatostatin Analog in Gastroenteropancreatic Tumors Other Than Carcinoid
}

\author{
Aaron I. Vinik, Ricardo Lloyd, and Kyung Cho
}

$\mathbf{G}^{\mathrm{u}}$ UT NEUROENDOCRINE TUMORS are thought to derive from common neuroectodermal cells within the gut/pancreas with the potential to differentiate into a variety of neuroendocrine tumors.' Gastrinomas account for approximately $20 \%$ of gastroenteropancreatic neuroendocrine tumors. Although these tumors are thought to be relentless and progressive with histological malignancy of $60 \%$ to $90 \%^{2,3}$ and $10 \%$ of patients die of metastatic disease, ${ }^{4}$ it is now recognized that there is a subvariety of benign gastrinomas, often small, in the wall of the duodenum that can be treated by surgical excision ${ }^{5}$ and tumors that may occur as part of the syndrome of multiple endocrine neoplasia type I (MEN-I) in which the management remains controversial. ${ }^{5-7}$ Latterly, it has been shown that a number of these neuroendocrine tumors are capable of synthesizing, storing, and secreting a variety of unrelated peptides, amines, and/or prostaglandins that are not necessarily clinically expressed in most cases, but in a proportion, multiple clinical syndromes may occasionally occur simultaneously or sequentially. ${ }^{8}$ For example, the occurrence of Cushing's syndrome in patients with pancreatic islet cell tumors first described in 1984 by Clark and Carney $^{9}$ is now thought to herald a more aggressive and relentless course of the condition. In these studies, we have examined the hypotheses that (1) somatostatin analogue (SMS, 201-995) blocks the action of gastrin at the target level on gastric acid hypersecretion; (2) SMS inhibits the hypersecretion of gastrin per se; (3) SMS controls tumor growth in metastases; (4) SMS exerts its antitumor activity by a vascular effect; (5) the effectiveness of SMS is a function of the tumorsecreting peptides other than gastrin; and (6) there are differences in susceptibility to SMS of metastases in different sites.

\section{PATIENTS}

The clinical details of our patients with the gastrinoma syndrome have been reported. ${ }^{6}$ Four patients had metastatic gastrinomas. Two patients had hypergastrinemic hyperchlorhydria and proved to have benign gastrinomas, one arising from the duodenal wall, another within the liver localized preoperatively by percutaneous transhepatic venous sampling. ${ }^{10}$ Both are normal 2 years after tumor resection. One patient had hypergastrinemic hyperchlorhydria, a pos-

From the Departments of Internal Medicine, Surgery, Pathology. and Radiology, University of Michigan, Ann Arbor, MI.

Supported by National Institutes of Health Grants No. IROICA49I77-01AI and 5MOI-RR-42 to the Clinical Research Center. During the course of these studies, Sandostatin was provided to patients at no cost by Sandoz, Inc, NJ.

Address reprint requests to Aaron I. Vinik, MD, Department of Internal Medicine, University of Michigan, Ann Arbor, MI 48109.

(C) 1990 by W.B. Saunders Company.

0026-0495/90/3909-2041\$03.00/0 itive secretin test and gastrin unresponsiveness to meal stimulation. Angiography and computed tomography (CT) scan were negative and transhepatic venous sampling (THVS) suggested localization of a tumor in the region of the triangle of the head of the pancreas, the wall of the duodenum, and pylorus. At laparotomy, only a peripancreatic lymph node in the region of the head of the pancreas was found that contained gastrinoma cells. After the operation, the patient did not improve substantially, acid secretion remained high, and treatment with SMS has been continued until the present. Histologic confirmation of gastrin producing tumors was obtained in seven of the 10 patients. Three patients did not have laparotomies and were diagnosed on the basis of raised basal and secretin-stimulated gastrin, increased basal acid secretion with a $\mathrm{BAO} / \mathrm{MAO}$ ratio of greater than 0.6 .

RESULTS

\section{Acute Effects of SMS}

Basal and secretin-stimulated gastrin was determined in these eight patients 6 hours after subcutaneous administration of $100 \mu \mathrm{g}$ SMS. SMS significantly lowered both basal and secretion stimulated gastrin. Of the eight patients, basal serum gastrin became normal in five and in only two did the secretinstimulated values fall below the upper limit of normal of less than $100 \mathrm{pg} / \mathrm{mL}$ increment above basal.

Acute effects of SMS on basal and pentagastrin-stimulated ( 6 to $12 \mu \mathrm{g} / \mathrm{kg}$ ) acid secretion were obtained in eight of 10 patients 1 hour after subcutaneous injection of $100 \mu \mathrm{g}$ SMS 201-995. Only in patients who had not had gastrectomies were studies of acid secretion performed. Antisecretory agents were discontinued 24 hours before study. Gastric juice, as well as blood samples, was collected during a 4-hour basal period, then at hourly intervals after subcutaneous administration of 50 to $100 \mu \mathrm{g}$ of SMS administered every 6 hours. Before SMS treatment, mean basal acid output was raised and the response to pentagastrin blunted, resulting in a high BAO/MAO ratio in gastrinoma patients. SMS lowered basal acid secretion from 25 to $2.6 \mathrm{mEq} / \mathrm{h}$, with an insignificant decrease in the pentagastrin-stimulated acid output, thus normalizing the BAO/MAO ratio. In seven of these eight patients, the BAO dropped to less than $5 \mathrm{mEq} / \mathrm{h}$.

\section{Long-Term Effects of SMS 201-995}

The long-term effects were studied in eight patients who were treated with 400 to $500 \mu \mathrm{g}$ SMS for 2 to 12 months. Biochemical responses were determined in five patients, two who had gastrectomies in whom only gastrin was measured and three who had basal and pentagastrin-stimulated acid studies and secretin tests after more than 5 months of treatment, before and 48 hours after withdrawal of SMS.

Basal gastrin gradually increased and basal acid output remained stable or increased slightly over a 3-year period. Secretin-stimulated gastrin remained abnormal in the three 
patients, but was suppressible by SMS both acutely and over a long-term period. Similarly, gastric acid responses to pentagastrin remained abnormal and no tachyphylaxis to SMS developed with time.

Six of the eight had improvement in their primary symptoms and two patients continued to have symptoms of abdominal pain, nausea, vomiting, and weight loss. Two patients who failed to respond had a progressive increase in gastrin concentration over a 7-month period. Despite increasing the dose to $1,000 \mu \mathrm{g} / \mathrm{d}$, gastrin levels remained elevated.

Three patients demonstrated important nuances not recorded heretofore and their histories and findings will be presented briefly.

\section{CASE REPORTS}

\section{Patient 1}

R.B. was a 39-year-old man who developed epigastric pain, increased bowel movements, and weight loss in 1979 and was diagnosed as having Zollinger-Ellison syndrome. Serum gastrin level at that time was between 20,000 and $40,000 \mathrm{pg} / \mathrm{mL}$. Upper endoscopy showed multiple ulcers and investigation showed a large pancreatic mass and multiple liver metastases. He underwent $80 \%$ pancreatectomy and left hemihepatectomy in March 1981. Postoperative serum gastrin level dropped to between 3,600 and $7,800 \mathrm{pg} / \mathrm{mL}$. In July 1981 , the patient developed basal acid secretion of $31 \mathrm{mEq} / \mathrm{h}$ while on a high dose of cimetidine and underwent a total gastrectomy. Chemotherapy using 5-fluorouracil and streptozotocin was started in view of multiple liver metastases. This was successful in suppressing the gastrin secretion to below $2,000 \mathrm{pg} / \mathrm{mL}$ for 2 years. Subsequently, the serum gastrin level increased again to $16,000 \mathrm{pg} / \mathrm{mL}$ and the metastatic tumors in the liver enlarged in size gradually despite chemotherapy and SMS treatment. Debulking of the tumor masses in the liver was performed and the patient was restarted on chemotherapy with little response. He subsequently developed overwhelming streptococcal pneumonia and disseminated pulmonary and cardiac aspergillosis and died. In the last 2 months of life, the patient was noticed to have a Cushingoid facies. Plasma cortisol level $(75 \mu \mathrm{g} / \mathrm{dL})$ and plasma ACTH level $(248 \mathrm{pg} / \mathrm{mL})$ were both elevated. The course is illustrated in Fig 1. No further biochemical test was performed as the patient was deemed too ill. Autopsy examination revealed enlargement of both adrenal glands to twice their normal size with microscopic hyperplasia. There was also widespread metastatic disease in the pancreatic bed and liver. The pituitary gland was normal.

\section{Patient 2}

D.K. is a 30-year-old woman who suffered from recurrent epigastric pain since 1969 at the age of 14 requiring regular antacid treatment. She developed bleeding duodenal ulcer at the age of 23 and underwent truncal vagotomy and pyloroplasty. Since then she had persistent ulcer pain and was treated with an $\mathrm{H}_{2}$-receptor antagonist. She had remained in relatively good health until I year before admission. She was evaluated for deterioration of ulcer symptoms and was found to have three distal antral ulcers and marked duodenal erosions at gastroduodenoscopy. Serum gastrin level was elevated to 1,700 (normal $<150) \mathrm{pg} / \mathrm{mL}$ and serum gastrin level rose to $5,496 \mathrm{pg} / \mathrm{mL}$ at 5 minutes after secretin-stimulation. Over the year, she also noticed the development of Cushingoid facies and hirsutism, acanthosis, and plethora with proximal muscle weakness. Urinary free cortisol concentrations were markedly elevated at $962 \mathrm{mg} / 24$ hours (normal $<0.5$ ). Plasma cortisol levels were elevated with a morning level of $40 \mu \mathrm{g} / \mathrm{dL}$ (normal 10-25) and evening level of $33.4 \mu \mathrm{g} / \mathrm{dL}$ (normal 3-16). Overnight dexamethasone test failed to suppress the morning plasma cortisol. However, the morning plasma ACTH level was normal at $76.6 \mathrm{pg} / \mathrm{mL}$ (normal 60-90). Plasma corticotropin-releasing factor (CRF) was $46 \mathrm{pg} / \mathrm{mL}$ (normal < 100). Plasma DHEA and testosterone were normal. CT scan of the abdomen showed a mass in the tail of the pancreas, but both adrenal glands were normal. CT scan of the pituitary was normal. Mesenteric angiography demonstrated a mass in the tail of the pancreas without apparent liver metastases.

She underwent laparotomy on September 19, 1985. A distal pancreatectomy with splenectomy was performed, removing a $5-\mathrm{cm}$ tumor. Both adrenal glands were found to be slightly enlarged. There was no evidence of metastatic tumor in the abdomen. Postoperatively, the basal serum gastrin level returned to normal at $135 \mathrm{pg} / \mathrm{mL}$, but the gastrin response to secretin-stimulation remained abnormal. The Cushingoid facies and the myopathy regressed within 2 months. The patient had no further evidence of active ulcer disease and cimetidine treatment was stopped. She also noticed regression of angioneurotic edema after the operation.

Histologic examination of the resected specimen confirmed the presence of an islet cell tumor. Immunohistochemical staining was positive for gastrin, ACTH, serotonin, $\alpha$ - and $\beta$-melanocyte-stimulating hormone (MSH), neuron-specific enolase, chromogranin, somatostatin, and vasoactive intestinal polypeptide. However, staining for corticotropin-releasing factor was, equivocal. Unfortunately, liver metastases were detected on CT scan 6 months after initial operation and both the basal serum gastrin and the response to secretin was now abnormal. Resection of a liver metastasis was performed out and the basal serum gastrin level returned to normal, but the response to secretin remained abnormal. Immunohistochemical staining of the metastatic tumor was positive for gastrin but negative for ACTH. In July 1988, she received a 2-week course of chemotherapy, including streptozotocin, 5-fluorouracil, and Adriamycin, with little response. In September 1988, the patient received chemoradiation of the hepatic metastases with yttrium 90 beads without arrest of progress of the tumor growth. In September 1988, she again noticed development of Cushing's features with elevation in plasma cortisol, which required medical treatment with aminoglutethimide. Her course is illustrated in Fig 2.

\section{Patient 3}

G.V. is a 19-year-old woman who had recurrent epigastric pain since 1983. In March 1985, she developed upper gastrointestinal bleeding from a duodenal ulcer. Laparotomy revealed a $7 \times 8-\mathrm{cm}$ mass at the tail of the pancreas, with large periportal lymph nodes and multiple liver nodules. Liver biopsy confirmed the presence of metastatic islet cell carcinoma. Vagotomy and oversewing of the ulcer was performed. A serum gastrin level was checked after the operation and was mildly elevated at $162 \mathrm{pg} / \mathrm{mL}$, with a peak level of $225 \mathrm{pg} /$ $\mathrm{mL} 5$ minutes after secretin infusion. Fasting cortisol was $11.7 \mu \mathrm{g} /$ $\mathrm{dL}$, and ACTH $60 \mathrm{pg} / \mathrm{mL}$. She was well until February 1986 when she developed frequent bouts of abdominal pain and vomiting. She also noticed the development of increased acne, facial puffiness, and truncal obesity. A secretin test showed a basal serum gastrin level of $220 \mathrm{pg} / \mathrm{mL}$, with a peak of $288 \mathrm{pg} / \mathrm{mL}$ at 10 minutes. Morning (8 AM) plasma cortisol level was elevated at $32.6 \mu \mathrm{g} / \mathrm{dL}$ (normal 10-25) and evening (10 PM) plasma cortisol was $18.8 \mu \mathrm{g} / \mathrm{dL}$ (normal 3-16). Both low-dose and high-dose dexamethasone administrations showed suppression of plasma cortisol to less than $5 \mu \mathrm{g} / \mathrm{dL}$ and plasma ACTH remained normal at $60 \mathrm{pg} / \mathrm{mL}$ (normal $<100 \mathrm{pg} / \mathrm{mL}$ ). CT scan of the abdomen showed numerous hepatic metastases with multiple masses in almost the entire pancreas. There were also numerous periaortic and pericaval lymph nodes, and both adrenal glands were slightly enlarged. She was diagnosed as having metastatic malignant gastrinoma with Cushing's syndrome. She was placed on treatment 
$10 \times$ Teis s.pu

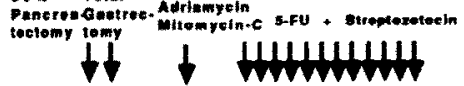
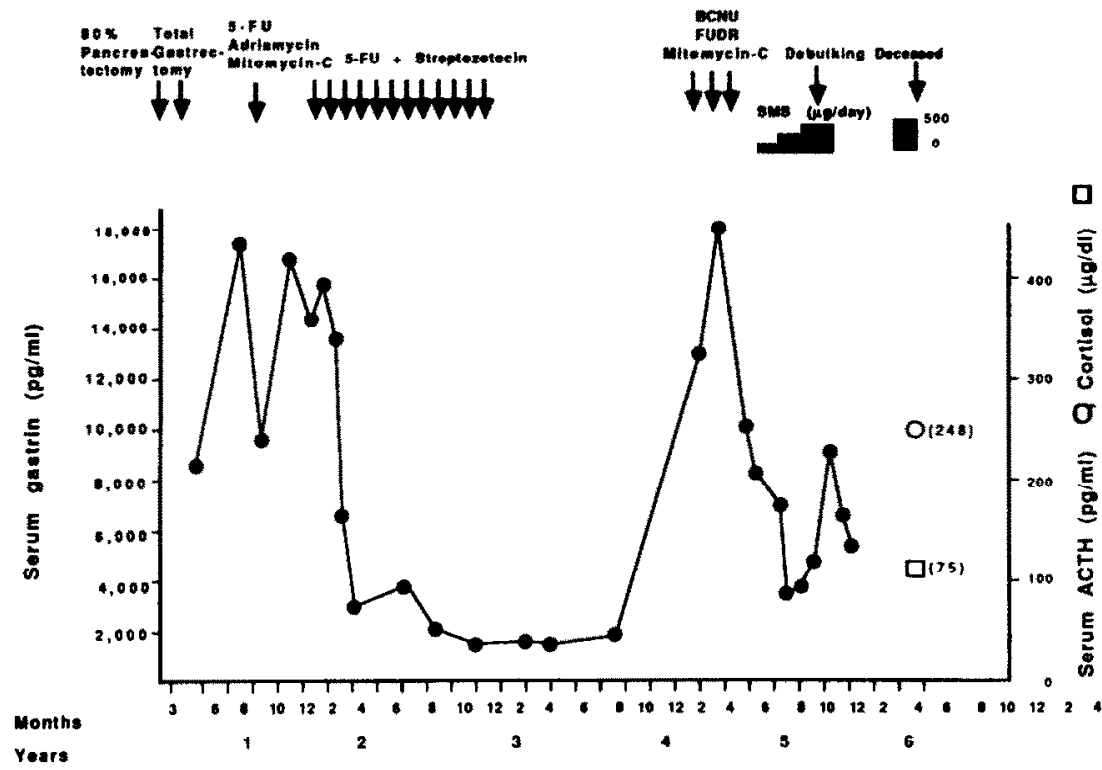

Fig 1. The course of R.B. with metastatic gastrinoma showing the initial responsa to an $80 \%$ total pancreatectomy and gastrectomy followed by chemotherapy with 5-fluorouracil, Adriamycin, mitomycin-c, and streptozotocin. Uitimately, after a period of $31 / 2$ years, the tumor escaped treatment and despite further chemotherapeutic agents and debulking of tumor metastases, the course was relentless and SMS appeared to have no effect. Terminally, the tumor appeared to produce ACTH or a corticotropin-releasing factor and cortisol levels increased with the development of Cushing's syndrome.

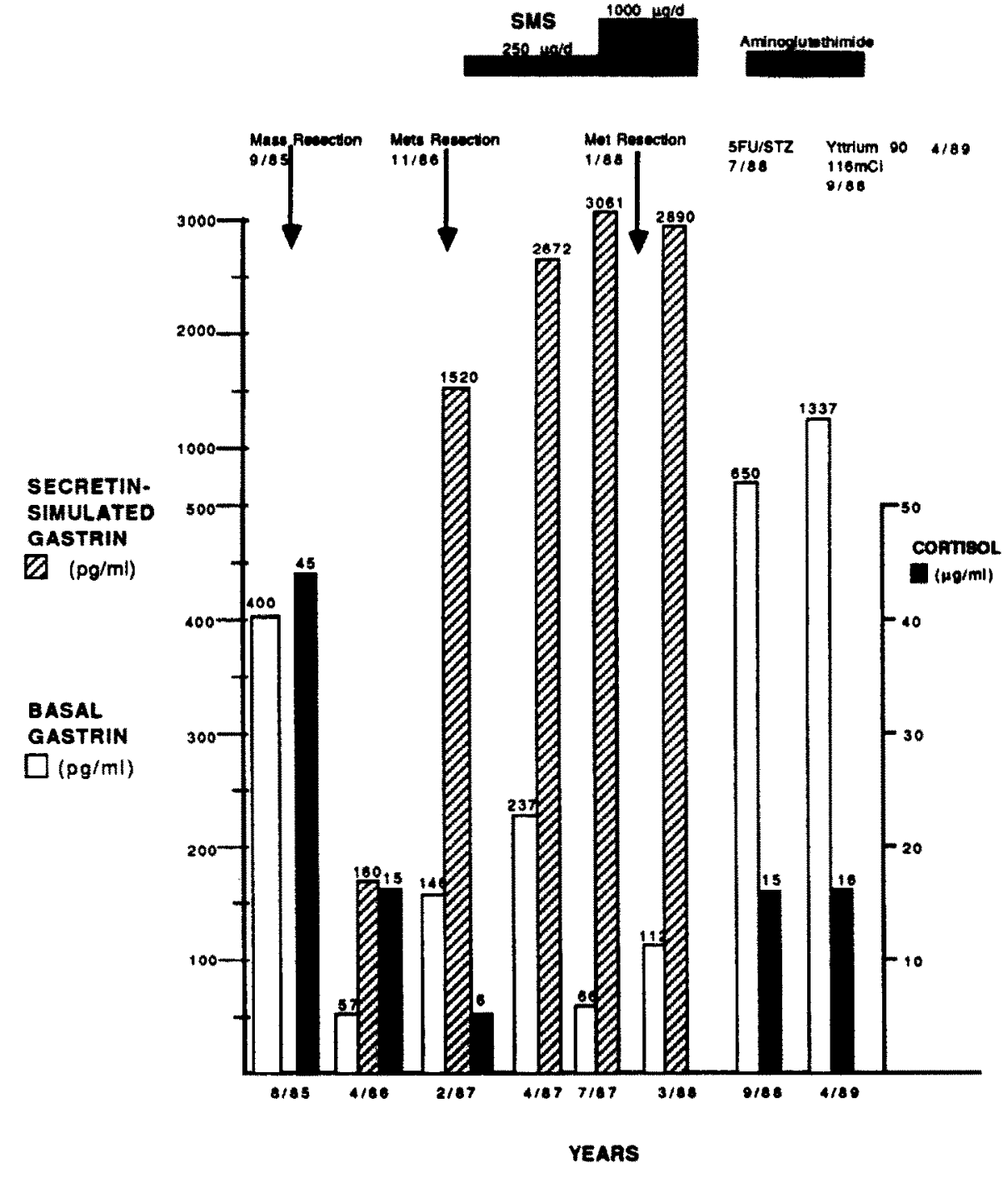

Fig 2. The course in D.K., a patient with a metastatic corticotropin-releasing factor (CRF)-producing tumor, in whom there was an excellent initial response to resection of the tumor mass and resection of a metastacis. Basal gastrin levels decreased, as well as cortisol, but the gastrin response to secretin remained abnormal indicative of per. sistence of the tumor. SMS was without effect and chemotherapy with 5-fluorouracil and streptozotocin was also ineffective. To control the Cushing's syndrome, aminoglutethimide was used and the tumor was brought under control with yttrium 90 perfusion of the liver metastases. 
with SMS in May 1986, with escalating doses from $200 \mu \mathrm{g} / \mathrm{d}$ to 2,000 $\mu \mathrm{g} / \mathrm{d}$ by April 1989. In March 1987, she had a bone scan because of complaints of generalized body pain and was found to have extensive bone metastases. Between March 1987 and April 1988, the patient received direct hepatic irradiation, but refused intrarterial chemotherapy. In October 1988, she developed right hip pain due to a pathologic fracture for which she received direct radiation. Her ulcer symptoms are controlled on SMS, and CT and angiogram in February 1989 showed a reduction in the liver and pancreatic masses. The course of her serum gastrin and gastric acid secretion are shown in Fig 3 and the reduction in hepatic metastases coincident with the development of bone metastases in Fig 4A-D.

\section{DISCUSSION}

Our 10 patients represent all three of the heterogeneous varieties of gastrinoma syndrome: the benign sporadic, MEN1, and the metastatic. All the benign tumors were found to be extrapancreatic and in sites similar to those previously reported. ${ }^{14.15}$ In eight of our patients with gastrinoma in whom we were able to evaluate acid secretion, SMS in doses of 50 to $100 \mu \mathrm{g}$ every 6 to 12 hours suppressed basal gastric acid secretion and restored the $\mathrm{BAO} / \mathrm{MAO}$ ratio to normal. The rapid and complete inhibition of gastric acid secretion led to a striking clinical improvement and made it possible to perform surgery without other forms of preoperative preparation. A single $50-\mu \mathrm{g}$ injection of SMS 201-995 was sufficient to control acid secretion for the duration of operation. ${ }^{26}$

Thirty-six months of therapy with SMS was able to reduce basal and pentagastrin-stimulated acid secretion with a return of responsiveness to pentagastrin and a normal BAO/MAO ratio. This occurred simultaneously with the reduction in basal and secretin-stimulated gastrin levels. However, with time, gastrin levels rose slightly as did acid secretion. There was no evidence for tachyphylaxis or receptor induction with continued treatment. Six of eight patients had excellent biochemical and clinical responses without evidence of tumor regression, but with an apparent cessation of tumor growth.

Two of our patients were quite unresponsive to SMS. The nonresponsive individuals who had high levels of gastrin had high $\mathrm{NH}_{2}$ : $\mathrm{COOH}$ terminal gastrin ratios. We have shown this to predict metastases and the ratio is of value in monitoring progress. ${ }^{23}$ However, we have not determined the impact of SMS on different molecular species of gastrin. The only apparent correlate of tumor response was with the level of the initial gastrin. It could not be predicted by the presence
Fig 3. Clinical course of patient G.V. is shown with a progressive increase in basal gastrin despite increasing doses of SMS. Earty in the course of her care she manifested signs and symptoms of Cushing's, but these disappeared with SMS treatment. After a 3-year period, the metastases to the liver appear to be controlled, whereas metastases to bone became extensive.

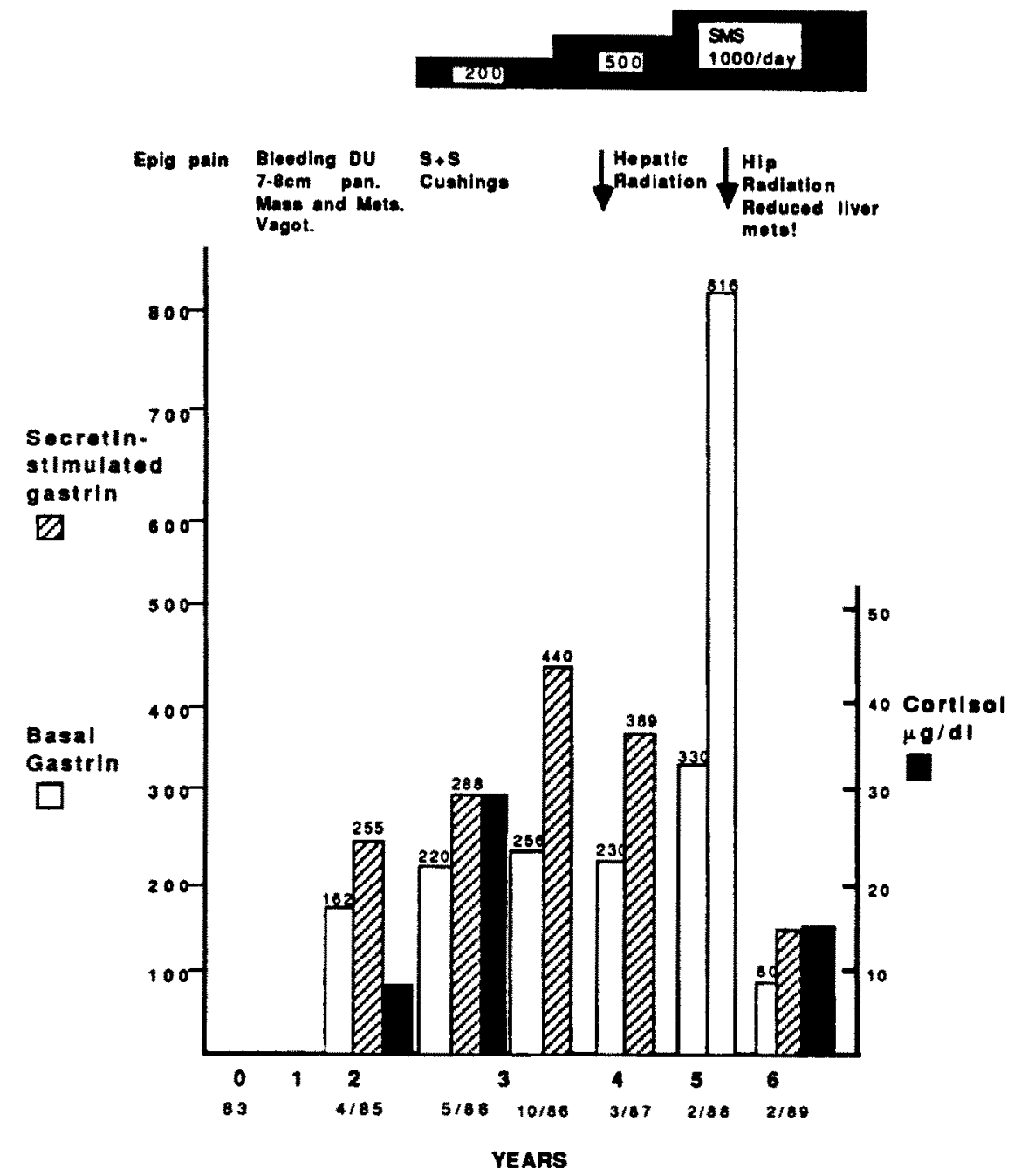



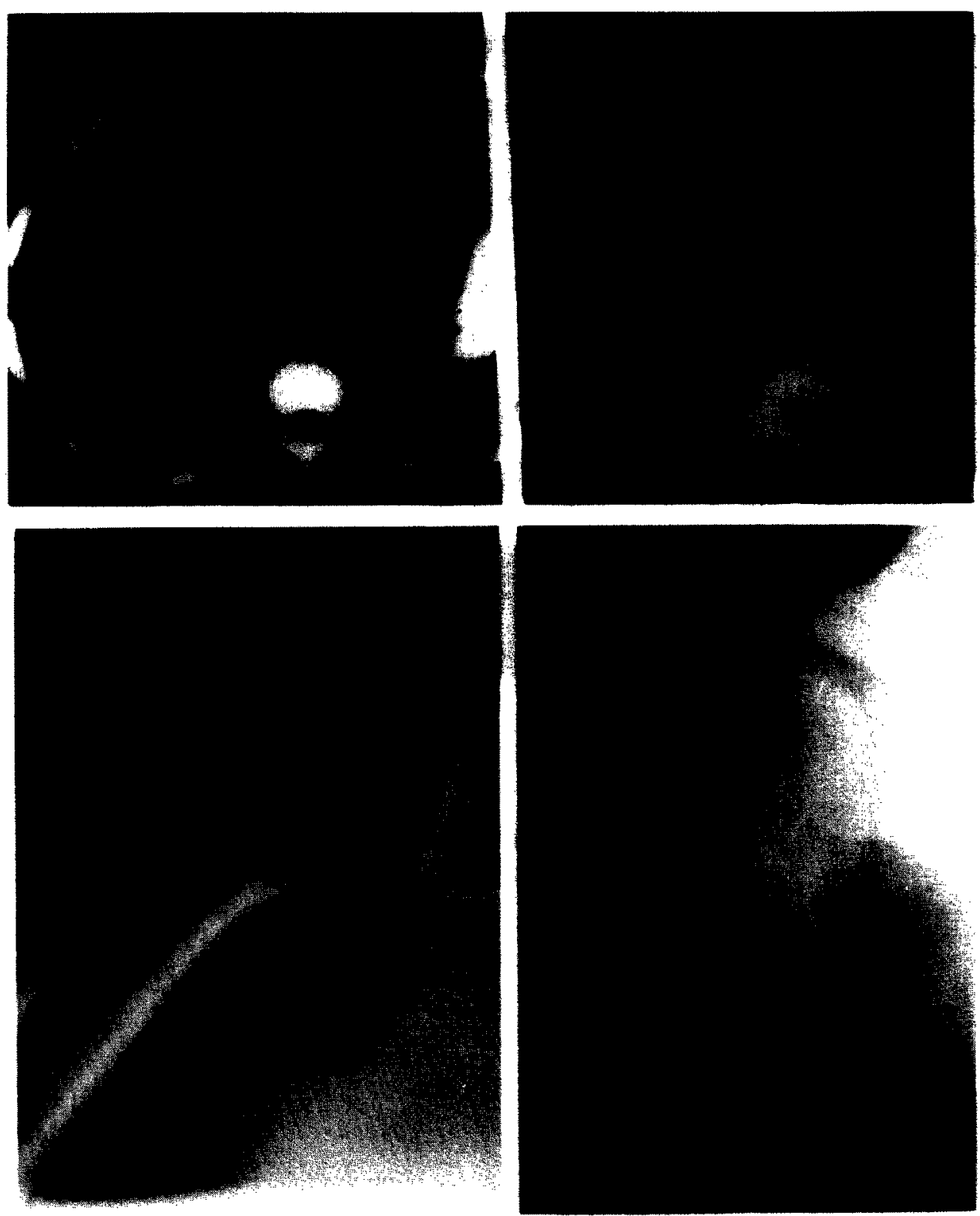

Fig 4. Gastrinoma tumor metastatic to the liver and bone in a 24-year-old woman. (A) An unenhanced CT section through the liver. Multiple, low attenuation metastases are seen throughout the liver. (B) Follow-up scan taken 6 months later showing slight improvement of the metastases. (C) Radiograph of the right shoulder taken at the time of CT of (A) showing no bony abnormality. (D) Repeat right shoulder $\mathrm{X}$-ray taken 1 year later showing metastases to the proximal part of the humerus.

or absence of metastases. However, the failure of SMS to lower gastrin did appear to parallel the lack of effect on tumor mass monitored by serial CT.

Both experimental ${ }^{18}$ and clinical findings ${ }^{18-20}$ suggest that it might be possible to use SMS as an hormonal therapy for some malignant gastroenteropancreatic endocrine tumors. Recently, in cases of vasoactive intestinal polypeptide (VIP)oma, SMS not only controlled the diarrhea, ${ }^{21}$ but also induced shrinkage of liver metastases after 5,6 , and 14 months of treatment. ${ }^{7,19,20,22}$ In contrast to the tumor response in VIPoma patients, gastrinomas appear to be more resistant to SMS although it has been reported that symptomatic im- provement occurred in six of nine patients with metastases treated with the analog. ${ }^{23}$ In our patients who had failed chemotherapy, SMS did not control tumor growth nor serum gastrin levels.

The mechanism of action of SMS may not lie in its direct effects per se. Incubation of the metastatic tumor with SMS did not inhibit release of gastrin but stimulated it, ${ }^{8}$ in contrast to findings reported by others. ${ }^{24}$ In the reported study, no distinction was made between the type of tumors and suppression of $\mathrm{Ca}^{++}$-stimulated and not basal gastrin was found. The unresponsiveness of metastatic tumors in vitro may reflect loss of receptors for $\mathrm{SMS}^{22}$ from undifferentiated 
tumors or the failure of SMS to release inhibitors of cell growth. Patients with the MEN-1 syndrome with gastrinomas have been reported as having a growth factor in their plasma that is capable of stimulating bovine parathyroid cell growth in culture. ${ }^{25}$ However, no data are available on the effects of SMS on the growth factor. Alternatively, SMS may affect tumor growth by altering local growth promoters or tumor blood flow. A reduction in tumor blood flow induced by SMS has been reported previously in one patient. ${ }^{7}$ However, further studies are required to establish this mode of action of SMS. Tumors that elaborate large amounts of gastrin appear to be refractory and there seems to be a relationship between cessation of tumor growth and the biochemical response. Also, it appears that secretion of hormones other than gastrin may alter responsiveness.

The simultaneous occurrence of Cushing's and ZollingerEllison syndromes has been reported before. ${ }^{26.27}$ In our three patients in whom the syndromes coexisted, ACTH levels were raised in only one of the three. All three of our patients had a long-standing history of Zollinger-Ellison syndrome before the occurrence of Cushing's syndrome. In two patients, there were already widespread metastases when Cushing's syndrome occurred and in one patient, liver metastases were detected soon after the appearance of Cushing's syndrome. The emergence of ectopic ACTH production associated with an advanced stage of malignancy is an interesting problem. A review by Clark and Carney in $1984^{\circ}$ showed that $88 \%$ of the pancreatic islet cell tumors associated with Cushing's syndrome had metastatic disease at the time of diagnosis. On reviewing the 12 patients with occurrence of both Cushing's and Zollinger-Ellison syndromes reported in the literature, 10 of them had metastases at the time when Cushing's syndrome appeared. One developed liver metastasis 6 months after the diagnosis and the last one, who had a malignant gastrinoma confirmed by histologic study, unfortunately died in the early postoperative period. A study of 30 patients with ectopic ACTH-producing tumors by Imura et al in $1975^{28}$ showed that adrenocortical hyperfunction was present in $61 \%$ at first examination and developed in a further $18 \%$ in the subsequent course of the disease. It was suggested that a specific cell line that elaborated ACTH might proliferate as the tumor progressed and reveal itself at an advanced stage of the disease. It was also suggested by Bustros and Baylin in $1985^{29}$ that the high frequency of ACTH production in malignant tumors might imply that the gene coding for ACTH was linked to genes involved in the progression of a malignant process. It is of interest that in one of our patients the tumor was positive for $\mathrm{ACTH}$, as well as MSH, suggesting the production of proopiomelanocortin by the tumor. Further understanding in the regulation of hormone gene expression in tumors by recombinant DNA techniques may provide clues to explain the observed association of ectopic corticotropin production in the advanced stages of malignancy. From the clinical point of view, the occurrence of Cushing's syndrome in patients with gastrinoma suggests a malignant process as illustrated in the clinical course of our patients. None of our cases were responsive to SMS and it seems that corticotropin production heralds unresponsiveness to the analog. ${ }^{6}$

\section{SUMMARY}

We have used the gastrinoma syndrome to examine the effects of SMS. Acutely, SMS decreased acid secretion and restored the $\mathrm{BAO} / \mathrm{MAO}$ to normal in eight of eight patients. Basal and secretin-stimulated gastrin responses were suppressed but not normalized. Treatment for up to 2 years with SMS controlled symptoms, suppressed serum gastrin, and suppressed acid secretion. Treatment for 1 year or longer decreased tumor secretion of gastrin and diminished basal acid secretion, an effect that persisted for $\mathbf{4 8}$ hours after withdrawal of SMS. SMS treatment arrested progression of tumor growth only in patients in whom there was a reduction in gastrin and gastric acid secretion. In patients with metastatic disease who had high levels of gastrin, SMS treatment for 5 to 24 months did not inhibit tumor growth or decrease gastrin levels. In those patients in whom a reduction in the blood flow to liver tumors was shown angiographically, there was a progressive improvement in hormone secretion and in tumor size in the ensuing year of treatment, suggesting that a major target of SMS is the vascular supply of the tumors. Tumors shown to produce peptides other than gastrin, for example ACTH, were found to be markedly resistant to the action of SMS and continued to grow in an unbridled manner.

\section{REFERENCES}

1. Vinik AI, Strodel WE, Lloyd RV, et al: Unusual gastroenteropancreatic (GEP) tumors and their hormones, in Thompson NW, Vinik Al (eds): Endocrine Surgery Update. Philadelphia, PA, Grune \& Stratton, 1983, pp 293-320

2. McCarthy DM: The diagnosis and treatment of gastrinoma and Zollinger-Ellison syndrome, in Santen RJ, Manni A (eds): Diagnosis and management of endocrine-related tumors. Boston, MA, Nijhoff, 1984, pp 347-382

3. Wolfe MM, Jensen RT: Zollinger-Ellison syndrome: Current concepts in diagnosis and management. N Engl J Med 317:12001209, 1987

4. Stabile BE, Passaro E Jr: Benign and malignant gastrinoma. Am J Surg 149:144-150, 1985

5. Vinik AI, Thompson NW: Controversies in the management of Zollinger-Ellison syndrome. Ann Intern Med 105:956-969, 1986

6. Vinik AI, Tsai ST, Moattari AR, et al: Somatostatin analogue
(SMS 201-995) in patients with gastrinomas. Surgery 104:834-842, 1988

7. Vinik Al, Tsai ST, Moattar AR, et al: Somatostatin analogue (SMS 201-995) in the management of gastroenteropancreatic tumors and diarrhea syndromes. Am J Med 81:23-39, 1986

8. Wynick D, Williams SJ, Bloom RS: Symptomatic secondary hormone syndromes in patients with established malignant pancreatic endocrine tumors. N Engl J Med 319:605-607, 1988

9. Clark ES, Carney JA: Pancreatic islet cell tumor associated with Cushing's syndrome. Am J Surg Pathol 8:917-924, 1984

10. Glowniak JV, Shapiro B, Vinik AI, et al: Percutaneous transhepatic venous sampling of gastrin. N Engl J Med 307:293-297, 1982

11. Kothary PC, Vinik Al, Owyang C, et al: Immunochemical studies of molecular heterogeneity of cholecystokinin in duodenal perfusates and plasma in humans. J Biol Chem 258:2856-2863, 1983

12. Kothary PC, Vinik AI, Mahoney WC: Identification of gastrin 
molecular variants in gastrinoma syndrome. Regul Pept 17:71-84, 1987

13. Vinik AI: Radioimmunoassay and bioassay of gastrin and somatostatin. J Clin Immunoassay 10:20-31, 1987

14. Whitehouse I, Beglinger C, Gyr K: SMS 201-995 (a long-acting, octapeptide, somatostatin analogue)-efficacy and duration of action after s.c. administration on pentagastrin-stimulated gastric acid secretion in man. Dig Dis Sci 29:96S, 1984 (suppl 8)

15. Thompson NW, Vinik AI, Eckhauser FE, et al: Extrapancreatic gastrinomas. Surgery 98:1113-1120, 1985

16. Tsai ST, Eckhauser FE, Thompson NW, et al: Perioperative use of a long-acting somatostatin analogue (SMS 201-995) in patients with tumors of the gastroenteropancreatic axis. J Surg 100:788-795, 1986

17. Schally AV, Comaru-Schally AM, Redding TW: Antitumor effects of analogs of hypothalamic hormones in endocrine-dependent cancers. Proc Soc Exp Biol Med 175:259-281, 1985

18. Wood SM, Kraenzlin ME, Adrian TE, et al: Treatment of patients with pancreatic endocrine tumours using a new long-acting somatostatin analogue: Symptomatic and peptide responses. Gut 26: $438-444,1985$

19. Kraenzlin ME, Ch'ng JLC, Wood SM, et al: Long-term treatment of a VIPoma with somatostatin analogue resulting in remission of symptoms and possible shrinkage of metastases. Gastrocnterology $88: 185-187,1985$

20. Clements D, Elias E: Regression of metastatic VIPoma with somatostatin analogue SMS 201-995. Lancet 1:874-875, 1985
21. Santangelo WC, O'Dorisio TM, Kim JG, et al: Pancreatic cholera syndrome: Effect of a synthetic somatostatin analog on intestinal water and ion transport. Ann Intern Med 103:363-367, 1985

22. Reubi JC, Maurer R, von Werder K, et al: Somatostatin receptors in human endocrine tumors. Cancer Res 47:551-558, 1987

23. Kvols LK, Buck M, Moertel CG, et al: Treatment of metastatic islet cell carcinoma with a somatostatin analogue (SMS 201-995). Ann Intern Med 107:162-168, 1987

24. Ellison EC, Woltering EA, Mekhjian TS, et al: Characterization of somatostatin inhibition of gastrin secretion in vivo and in vitro. Proceedings of the Symposium on Gut Endocrinology, Clinical and Therapeutic Impact. Am J Med 815:55-64, 1986

25. Brandi ML. Aurbach GD, Fitzpatrick LA, et al: Parathyroid mitogenic activity in plasma from patients with familial multiple endocrine neoplasia type I. N Engl J Med 314:1287-1293, 1986

26. Geokas MC, Chun JY, Dinan JJ, et al: Islet-cell carcinoma (Zollinger-Ellison syndrome) with fulminating adrenocortical hyperfunction and hypokalemia. Can Med Assoc J 93:137-143, 1965

27. Law DH, Liddle GW, Scott JR, et al: Ectopic production of multiple hormones (ACTH, MSH, and gastrin) by a single malignant tumor. N Engl J Med 273:292-296, 1965

28. Imura H, Matsukura S, Yamamoto H, et al: Studies on ectopic ATCH-producing tumors. II. Clinical and biochemical features of 30 cases. Cancer 35:1430-1437, 1975

29. Bustros AD, Baylin SB: Hormone production by tumors: Biological and clinical aspects. Clin Endocrinol Metab 14:221-256, 1985 